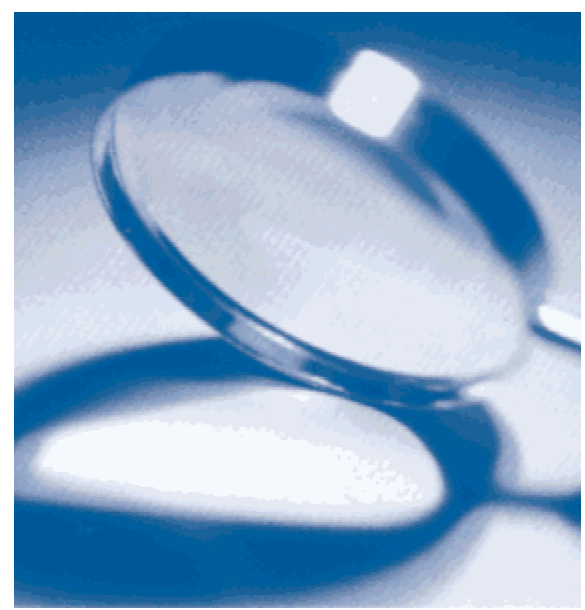

In the Public Eye

News and Features

\title{
Controversy erupts over reuse of "single use" medical devices
}

Fred Charatan, Florida

Hospital and clinic instruments are being reused despite their "single-use" designation. Vanguard Medical Concepts of Lakeland, Florida claims to have cleaned and resterilized instruments such as biopsy forceps and wires and balloons used for coronary or cardiac procedures.

Charles Masek, president of Vanguard Medical Concepts, said that his company has reprocessed more than 2.5 million devicesranging from coronary angioplasty balloon catheters and orthopedic blades, burrs and bits to deep vein thrombosis sleeves and laparoscopic instruments. Vanguard is a founding member of the Washington-based Association of Medical Device Reprocessors.

The manufacturers of medical devices have said that hospitals are putting patients at grave risk to save money. "The real issue is patient safety," said Josephine Torrente, president of the Association of Disposable Device Manufacturers. "Until you prove otherwise, these devices are safe and effective for one use. After that, they're garbage."

Larry Kessler, director of the office of surveillance and biometrics at the Food and Drug Administration, said: "There are no products where we have significant evidence that there is immediate harm to the public health." His view is shared by William Jarvis, head of the infections and prevention branch of the hospitals' infection program, at the Centers for Disease Control and Prevention.

Despite this reassurance, many hospitals remain wary. "Given the fairly convincing evidence that high temperatures and caustic chemicals change the nature of materials, I'd

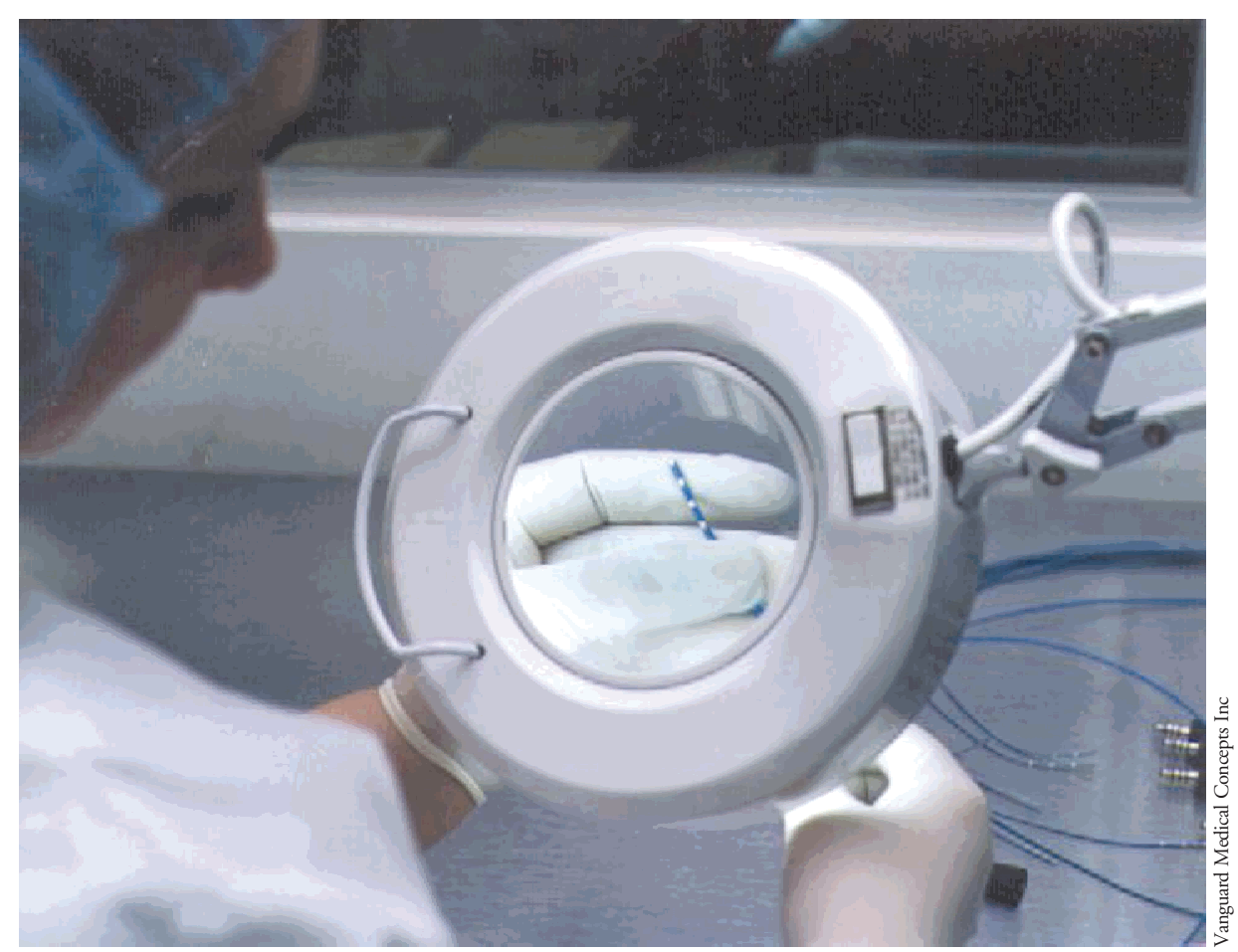

Reprocessing single use instruments: is regulation needed? 
be leery of using redisposables," said J P Abenstein, chairman of the equipment subcommittee at the Mayo Clinic in Rochester, Minnesota.

The Food and Drug Administration has proposed a strategy designed to protect the public health by assuring that the practice of reprocessing and reusing single use products is based on good science. The administration would thus consider regulating third party processors of single use devices the same way as it has regulated the manufacturers of equipment.

Full details are available on the Internet at www.fda.gov.

\section{International report reassesses ways to cut maternal mortality}

James Ciment, New York

Deaths in pregnancy cannot be reduced by the existing method of targeting high risk women, says a study by the World Health Organization, the United Nations Population Fund, Unicef (the United Nations Children's Fund), and the World Bank. The study questions a number of long held beliefs about maternal mortality. Assessing 10 years of work in the field, the report (Reduction of Maternal Mortality) insists that "vertical, standalone" measures cannot alone effectively reduce the near 600,000 annual deaths caused by pregnancy and childbirth complications.

According to Koen Vanormelingen, a senior health adviser for Unicef and one of the report's authors, the existing prenatal care risk approach-which attempted to target women at high risk - "is not very effective in reducing mortality." The correlation between factors such as a history of obstructed birth, says Vanormelingen, is far from exact. "Any women is at risk and can suffer life threatening complications," he added.

Rather than focusing on high risk women, the report argues that the most effective means for reducing maternal mortalityusually caused by extensive haemorrhagingis to assure that every woman has a skilled attendant at birth or, at the very least, access to essential obstetric services if there are complications. Moreover, says Vanormelingen, research behind the report finds that tradi- tional birth attendants—once considered a useful substitute for trained midwives and doctors_- "will not by themselves reduce maternal mortality."

Citing Sri Lanka as a case study, the report connects the south Asian nation's reduction in maternal mortality-from 550 to 30 per 100,000 births over the past four decadesto the fact that the once predominant practice of home births without trained staff in attendance had been replaced by skilled birth attendants in over $85 \%$ of the cases.

The report also notes that "the low social and economic status of girls and women is a fundamental determinant" of high maternal mortality in many developing countries.

\section{Furby not guilty as "charged"}

Greg Basky, Saskatoon, Canada

It seems now that Furby, a stuffed toy with a computer chip inside, which was vilified for interfering with medical equipment, does not affect medical machinery after all. An investigation by Health Canada (the government's health ministry), published recently in the Canadian Medical Association Journal (1999; 161:971), revealed that the electric and magnetic fields given off by the ear wiggling, eye blinking, fuzzy creature are about 70 times weaker than those emitted by a digital telephone and are "very unlikely" to affect the performance of medical devices, say the study's authors.

The furry furor started last January, when Canadian media outlets jumped on reports that the Royal Hospital for Sick Children in Glasgow, Scotland, had apparently banned the toy from its intensive care unit. No Canadian hospitals barred visitors bearing the creature.

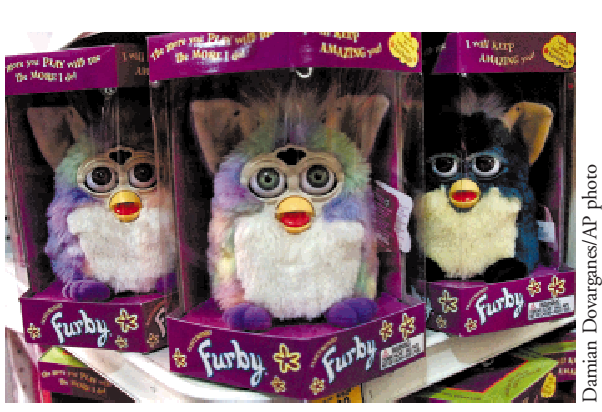

Furby: innocent of all charges of interference

In response to media coverage and calls from biomedical engineers, researchers in Health Canada's Medical Devices Bureau measured the effect of Furby on 10 devices made before 1993 and known to be vulnerable to interference from cellular phones. These included incubators, automatic external defibrillators, syringe pumps, infusion pumps, electrocardiogram monitors, ventilators, renal dialysis machines, and pacemakers.

Three other machines (the Holter monitor, an anesthetic system, and an ultrasound system) produced before 1996 were also studied because of concerns about possible susceptibility to electrical interference.

Furby was given a clean bill of electromagnetic health, as it did not adversely affect the functioning of any of the devices tested at any distance. While the chattering creature did generate electric and magnetic fields in its active mode (it awakens from hibernation in response to sound and light), these were too weak to pose any threat to hospital equipment.

Dr Kok-Swang Tan of Health Canada admits that during the testing he did get some "strange looks from colleagues who wondered why I was playing with a Furby in front of medical devices." 


\section{Missouri fines Internet pharmacy}

Douglas Carnall, London

An Internet pharmacy that supplied prescription only drugs without appropriate medical supervision has been fined $\$ 15,000$ by the state of Missouri and will have to reimburse all its customers for any charges. As is typical for such Internet pharmacies the site concentrates on supplying the so-called lifestyle drugs such as sildenafil (Viagra), finasteride (Propecia), orlistat (Xenical) and bupropion (Zyban).

The site (http://thepillbox.com) is based in San Antonio, Texas, and its owner, William
Stallknecht, stood as a Libertarian party candidate for the US House of Representatives in 1998. The case against the pharmacy was brought by a pregnant assistant attorney who found that she was able to order Propecia (although the drug is contraindicated in pregnancy) after filling out an online questionnaire.

Guidelines of the American Medical Association declared this practice unethical earlier this year (www.bmj.com/cgi/content/full/ 319/7204/213)."We picked a major operation with significant resources and took them on, making sure that they are fully represented," said Missouri attorney Jay Nixon, "and shut them down as a clear signal to everyone else out there that this is illegal conduct in our state" (www.slfp.com/ 072399city.htm).

Customers at thepillbox.com website paid $\$ 85$ for an online "consultation" before ordering drugs, but the Texas doctor who was writing the prescriptions, James Reed Williams, has agreed that he will no longer sign prescriptions for Missouri residents.

\section{Doctors feel the pressure from direct to consumer advertising}

David Spurgeon, Quebec

Most physicians whose patients asked them about drugs they had seen advertised in the media felt under pressure to prescribe them, according to a telephone poll reported at the annual meeting of the American Association of Pharmaceutical Scientists. In 30 to $36 \%$ of such cases, the physicians gave in to the pressure, even when the drug in question was not their first choice.

The poll was conducted among 199 pri- mary care doctors practicing in Ohio and Pennsylvania during January and February 1999 , including those who were described as high prescribers of statins. Respondents were offered an honorarium of $\$ 75$ for participating. Respondents to the poll, which was carried out by Benjamin Banahan, professor of pharmacy administration and John Bentley, assistant professor of pharmacy administration, at the University of Mississippi, indi-

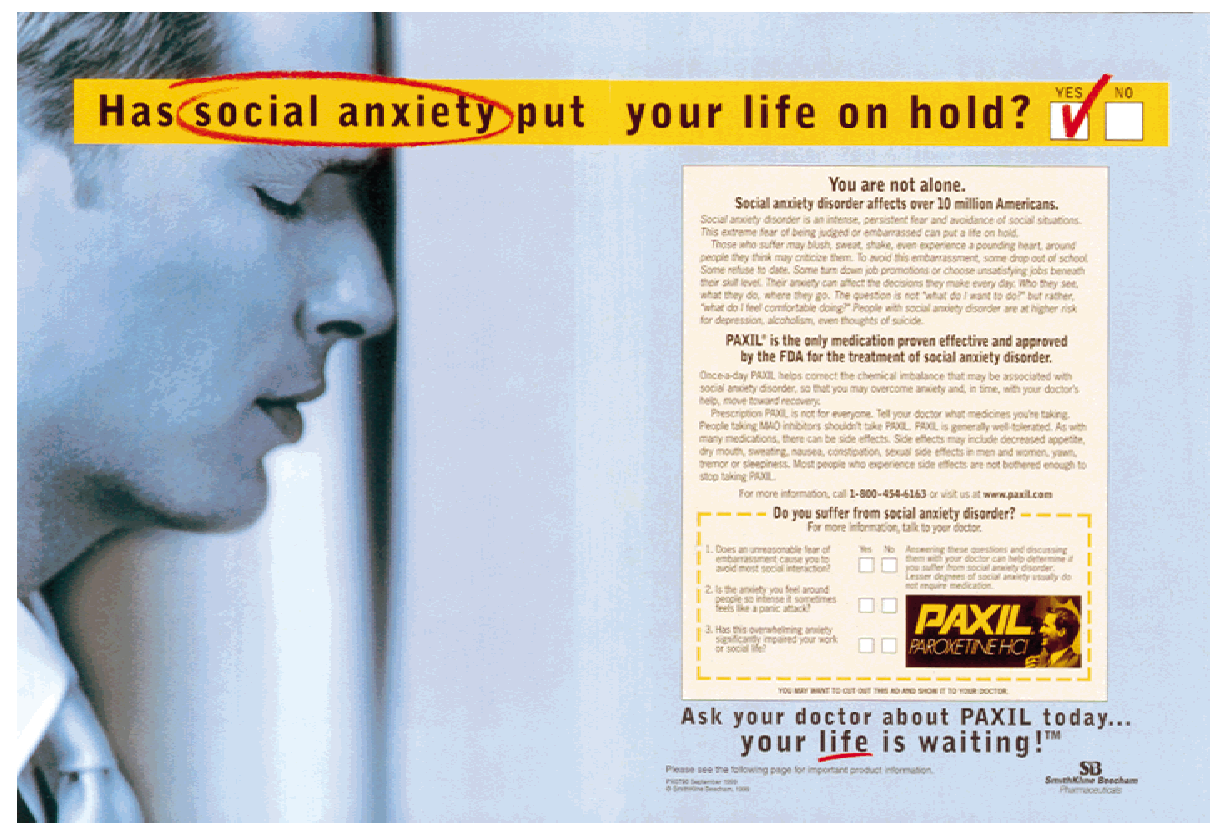

cated that on average five patients a week asked them to prescribe a specific product, and $30 \%$ of the time they did so.

The physicians said that television advertisements were the most frequent source of their patients' information (77\%); print advertisements were next $(51 \%)$, followed by television news stories (49\%) and print news stories $(48 \%)$. More than half $(52 \%)$ of the doctors thought that the information in prescription advertisements was only partially accurate, and $42 \%$ thought it was mostly accurate.

Altogether, $91 \%$ of the physicians who responded reported that they felt under pressure to prescribe products patients asked them about: $38 \%$ reported "very little" pressure, $47 \%$ "a little" pressure, and 6\% "a lot" of pressure. The American Medical Association reversed its stand opposing direct to consumer advertising in 1992.

Professor Banahan said that physicians today were more likely to respond to pressure from patients to prescribe than they were in the past. Those who responded to pressure to prescribe a drug that was not their first choice said that they considered that the drug they ended up prescribing was acceptable. The project was supported by a research grant from the R W Johnson Pharmaceutical Research Institute, a research arm of Johnson and Johnson. 


\section{Health situation in former communist bloc is dire, says Unicef}

James Ciment, New York

Marking the tenth anniversary of the fall of the Berlin Wall, the United Nations Children's Fund (Unicef) has issued a report on the social ramifications of the transition to market economies in the former communist bloc.

The report, After the Fall: the Human Impact of Ten Years of Transition, states that women and children have suffered especially hard. Although the report chronicles a host of economic and social problems, its findings on health are particularly disturbing, especially on the reappearance of so called poverty diseases.

The number of cases of diphtheria in Russia and Ukraine rose from about 1900 cases in 1990 to 43,000 in 1998. Poliomyelitis, which had been virtually eliminated in the former Soviet Union, has reappeared in the Central Asian Republics and Ukraine.

Tuberculosis is also on the rise in the western parts of the former Soviet Union, with children accounting for over 10\% of new cases. Cases of sexually transmitted diseases are increasing as well.

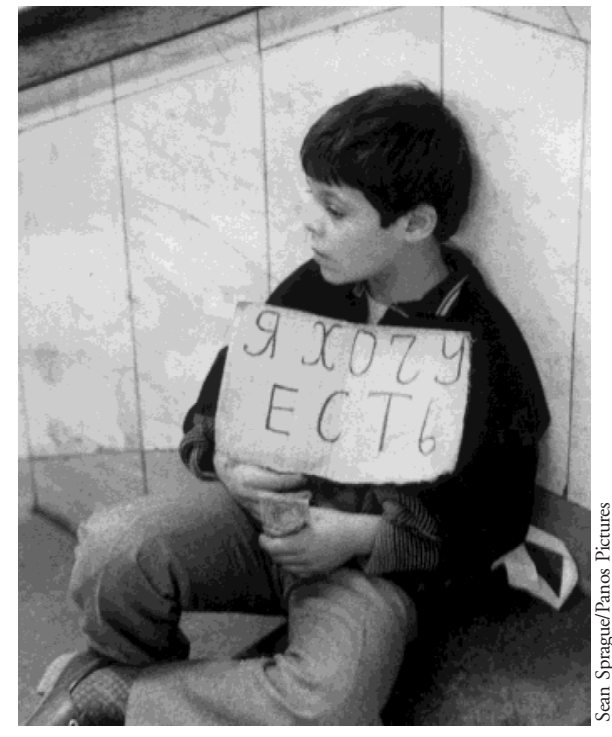

"I want to eat" - poverty is hitting Russian children hard

Syphilis, practically eliminated by 1990 , has re-emerged in the former Soviet Union, with some 221 cases per 100,000 people in 1998, more than 100 times the average of the European Union.
Meanwhile, the number of cases of HIV infection in the western part of the former Soviet Union had climbed from 30,000 in 1994 to 270,000 by the end of 1998 . "It is safe to say," the report argues, "that these areas now face an epidemic of HIV and AIDS."

Several factors are behind these disturbing trends, the reports' authors conclude. Although some countries in the region have fared better than others in terms of health statistics, every single one has cut its spending on health care over the past 10 years. Meanwhile, the despair caused by economic collapse has led to soaring drug misuse, alcoholism, injury, and suicide rates among young people. In the Czech Republic, for example, teenagers aged 15 to 19 were twice as likely to end their own lives in 1994 as they were in 1990.

Asked to cite any encouraging signs in the region, Patrick McCormick, a spokesperson for Unicefs Research Center in Florence, which published the report, said, "there is a freedom now." But, he added, "children are paying too high a price for that freedom and they are not in a position to benefit from it."

\section{Big health insurer gives physicians final say in treatment}

Fred Charatan, Florida

The United Health Group, the second biggest managed care company in the United States, has told physicians that they will no longer require prior approval before carrying out most medical and surgical procedures. It is closing its utilization review division, which runs its prior authorization procedures.

The group-which insures 14.5 million people, including 8.7 million in managed care units-found that requests for approval of care were almost always granted; it had been denying coverage in fewer than $1 \%$ of all precertification decisions.

The company said that it was taking the final say out of the hands of the managed care bureaucracy and returning it to the treating physician, because requiring doctors to get prior authorization was costing more money than it saved. The division cost $\$ 128 \mathrm{~m}$ to run last year.

The group's decision was possible, in part, because the company is one of the few large health care plans that has succeeded in using computers to track the behavior of its 42,000 doctors in 17 states and compare costs and patient outcomes. These include such indicators as whether doctors prescribed beta blockers after heart attacks and ordered mammograms to women aged over 50. "That quality measurement program is the reason we felt comfortable doing this," said Lee Newcomer, the group's medical director.

Thomas Reardon, president of the American Medical Association, said: "This action is historic and represents a long overdue victory for America's patients and the care they receive."

Susan Pisano, spokeswoman for the American Association of Health Care Plans, said that utilization review still had a role in holding down unnecessary procedures. "It has the effect of saving money, but the primary consideration is to reduce the dangerous level of variation we see in a lot of procedures."

She cited evidence that operations such as hysterectomies were much more likely to occur in some geographic regions than others. Some health care analysts said that, overwhelmed by consumer and regulatory backlash (and faced with a presidential campaign in which managed care is a leading issue), the industry was beginning to change. 